\section{CONDENSATION NUCLEI}

\section{SYMPOSIUM IN DUBLIN}

A SYMPOSIUM on condensation nuclei was held in the School of Cosmic Physics, Dublin Institute for Advanced Studies, during April 26-28, when thirty-four delegates from eight countries participated and twenty-six papers were presented. The five half-day sessions dealt with the meteorology, climatology and aerology of nuclei, new instruments and methods for recording their concentration, measuring their gize, density and mass, their biological role and importance for research in hygiene and the production of nuclei under special conditions.

The relationship between the concentration of atmospheric nuclei measured with a photo-electric counter twice daily over a four-year period at Valentia Observatory and meteorological elements has been investigated by S. McWilliams and W.A. Morgan (Ireland). The majority of observations gav $\Theta$ a count of less than 500 nuclei cm.-3 ${ }^{-3}$ the concentration generally decreased with increasing relative humidity and the annual variation followed fairly closely that of duration of bright sunshine.

M. Bider (Switzerland) presented a similar investigation for Basle based on continuous records obtained by means of the automatic Verzár photo-electric nucleus counter. Since this recorder measures concentration every fifteen minutes, many problems can be tackled which with eye observations at a few fixed hours could not be approached. The increase of concentration with sunshine established near the Atlantic at Valentia was also found at Basle. Simultaneous records with identical Verzár automats in the centre of the city and on the outskirts at a distance of $1.5 \mathrm{~km}$. have shown that the average concentration in the centre $\left(46,000\right.$ nuclei $\left.\mathrm{cm}^{-3}\right)$ is about eight times that on the outskirts. In spite of this very large difference in the concentrations, the variation at both stations was strikingly similar.

G. J. Day (Meteorological Research Flight, Farnborough) delivered a preliminary report on measurements of condensation nuclei made with a direct-beam photo-electric counter during ten aeroplane ascents over the British Isles in mainly anticyclonic situations. He found that clean maritime air passing over unbroken sea surfaces contains about $200 \mathrm{~cm} \cdot{ }^{-3}$ nuclei at normal cloud-base levels (approximately 2,000 ft.), though it often contains as many as $3,000 \mathrm{~cm} .^{-3}$ nuclei in the lowest few hundred feet. Over broken sea surfaces values of $1,000 \mathrm{~cm}^{-3}$ nuclei are found throughout the turbulent mixing layer, so that it appears that sea salt nuclei contribute a large, though not a major, part to the nucleus population. At heights of 1,000-2,000 ft., during flights covering most of England and including some circumnavigations of Greater London, a normal concentration of about $2,000 \mathrm{~cm}^{-3}$ nuclei was found which rose to $5,000 \mathrm{~cm}^{-3}$ nuclei over large domestic and industrial centres. Contrary to expectation, no increase in the general level of concentration downwind of large contaminating centres such as London was found. However, downwind of specific sources within such areas, concentrations of tens of thousands of nuclei per cm..$^{3}$ often thirty thousand, were observod. These localized increases seem associated with a relatively few sources and must presumably be associated with spocific industrial processes.
Mrs. Rita Callahan Sagalyn (United States Air Force Cambridge Research Center) reported on concentration, mobility and distribution of charged nuclei in fair weather and in the altitude-range 500-20,000 ft. These investigations over the United States and the Atlantic Ocean were carried out together with G. Faucher in a B-17 aeroplane converted into a veritable flying observatory. A series of diurnal measurements made over a fixed flightpath indicates the importance of turbulence and airmass changes for the distribution of nuclei in the atmosphere.

New ingenious methods for counting nuclei, which J. C. Thams and W. Wieland (Locarno-Monti) have recently developed, were described and illustrated by Dr. Bider. The droplets formed by expansion in an Aitken-Scholz counter, and even the nuclei themselves before forming cores of droplets, are caught on slides coated with a thin $(0.01 \mathrm{~mm}$.) layer of copal lacquer in which they produce holes. The counting of the holes is rapidly carried out by a photo-electric device.

Great progress in recording nuclei concentration is noticeable in the second version of the automats designed by F. Verzár (Basle) and the construction by R. Siksna (Uppsala). Both elaborate automats employ the direct-beam photo-electric principle, and the latter in addition uses continuous photographic recording of the droplets in an Aitken-type counter. R. Mühleisen's (Western Germany) new recorder for nuclei concentration with continuous over-saturation, which hitherto had escaped general notice, has the advantage of recording concentration in one-minute intervals.

Recently in meteorology there has been a tendency to seek information on the size of the condensation nuclei and their nature as well as their concentration. $A$ variation of the photo-electric nucleus counter to obtain size discrimination was demonstrated by T. A. Rich (General Electric Company, United States). The sample at atmospheric pressure in tho fog-tube of the counter is expanded into two evacuated containers : into one as rapidly as possible, into the other slowly enough to permit the growth of water drops and yet fast enough so that the expansion is essentially adiabatic.

Preliminary tests of a new method for measuring the size, density and mass of condensation nuclei which L. W. Pollak and T. C. O'Connor (School of Cosmic Physics, Dublin) have designed for investigating the quickly changing atmospheric aerosol, particularly during aeroplane flights, are encouraging. The underlying theory of this 'static' method was developed by R. Fürth (Birkbeck College, University of London). Utilizing standard equipment and measuring the decreasing concentration of condensation nuclei when enclosed in a small cylindrical container, it is possible to determine from two measurements of concentration the size of the nuclei and from three such measurements their size, density and mass.

P. J. Nolan and E. Kuffel (University College, Dublin) dealt with the decay of enclosed nuclei. They found with ultra-small nuclei that the coefficient of the linear diffusion term in the decay equation varies as the square root of the diffusion coefficient. The production of nuclei from ammonia and nitric acid were discussed by P. J. Nolan and E. Kuffel ; that of uncharged nuclei by ultra-violet light formed. the subject of a most interesting paper by $J$. R. Atkinson (Glasgow), whose results are also of importance for users of cloud chambers. 
The retention of condensation nuclei in the respiratory tract was dealt with by $F$. Verzár and P. J. Nolan. Based on experiments made by $T$. Burke and himself, Nolan stated that nuclei are not produced by breathing. Exhaled air contains 80-20 per cent of the nucleus content of the inhaled air. Mr. Claes Rooth summarized most ably the important work by C.-G. Rossby (Stockholm) and H. Egnér (Uppsala) on the synoptic variations in the chemical composition of atmospheric precipitation and made a strong plea for introducing measurements of carbon dioxide as a routine in meteorological networks.

In the geophysical laboratory of the School of Cosmic Physics, Dublin, equipment for determining concentration and size of condensation nuclei and for measuring their vertical gradient near the ground were demonstrated during the symposium. A small exhibition showed the development of the photoelectric nucleus counter. Among the exhibits were a photograph of the direct-beam photo-electric nucleus counter, and the original model of the multiflex photo-electric counter which L. W. Pollak designed and W. A. Morgan constructed in the offices of the Irish Meteorological Service at Foynes early in 1940. The proceedings of the symposium will be published as a separate volume of Geofisica Pura e Applicata (Milan). The next symposium on condensation nuclei is to take place in September 1956 in Switzerland.

L. W. Pollak

\section{TAPEWORMS OF THE FAMILY TETRABOTHRIIDAE}

A

$\mathrm{N}$ interesting and important paper by Prof. J. G. Baer has been published as a memoir of the University of Neuchâtel* on a taxonomic revision and biological study of the Cestodes of the family Tetrabothriidae parasitic in birds of the high seas and marine mammals. In the paper, Prof. Baer aims at classifying and simplifying the determination of this very difficult group of tapeworms, and seeks to show-with considerable success - that a parasite and its host are fundamentally inseparable. 'The two must be considered together.

The revision is based on the re-examination of more than seventy types of the eighty-odd species described, with the result that the number of species is reduced to forty, and only four of the eleven genera are retained. The monograph is divided into five sections, the first three of which are entirely given up to the descriptions of the species together with their synonyms, hosts and the more important bibliographical references. An introductory chapter deals with the general anatomy, and it is found that neither the size of the scolex nor the muscular development of the strobila are reliable taxonomic characters, as was formerly supposed to be the case. On the other hand, the structure of the genital atrium is stressed since it appears to yield by far the best and most reliable morphological character. This structure, however, can only be seen in transverse sections, and therefore no specific identification is possible if worms are mounted in toto. All the species

* Révision taxonomique et étude biologique des Cestodes de la famille des Tetrabothridae parasites d'oiseaux de haute mer et de mammifèrés marins. By Jean G. Baer. Mémoires de l'Université de Neuchatel, Série. in-quarto, 1 ; 1954. Tp. $123+82$ flgs.. (Neuchátel, 1954.) 20 Swiss francs. are described in a uniform manner, and only the essential characters are stressed. The genital atrium of each species is illustrated, and all the drawings made to the same scale, so that comparisons are easily made, while a special section is devoted to the comparative anatomy of the species. It is found that the structure of the genital atrium reveals the existence of three distinct evolutionary trends, making it possible to split the species into distinct groups. A key for the identification of the species is thus established. The position of the family Tetrabothriidae is discussed and it is assigned to a new order, distinct from either the Pseudophyllidea or the Cyclophyllidea, but more closely related to the Tetraphyllidea.

Tetrabothriids are found to be extremely hostspecific; each group of hosts-namely, Sphenisciformes, Procellariiformes, Pelecaniformes, Gaviiformes and Charadriiformos-harbours species distinct from those occurring in the others. Although the life-cycle of the tapeworms is unknown, it is postulated, on the basis of stomach contents of the sea-birds and mammals, that cephalopods might act as intermediate hosts. From statistical evidence it seems that the host can only become infested when leading a semi-sedentary life, that is, during the breeding season. This is also borne out by the fact that different hosts belonging to the same order nesting on the same island usually harbour the same species of tapeworm. Using the evolutionary trends of the genital atrium as a basis, combined with the results obtained from a statistical study of the distribution of the parasites among the hosts, it is found that there is distinct evidence of parallel evolution of both the tapeworms and their hosts. From these results it is postulated that the Sphenisciformes, Procellariiformes and Pelecaniformes might be derived from a common stock, and the Gaviiformes and the Alcae appeared later as side branches. The arguments and evidence put forward here by Prof. Baer are convincing, and one feels that his main conclusions are right. He also suggests that the species harboured by gulls have been acquired secondarily. But here he is not quite so confident; the case is certainly more open to argument, and one wonders if perhaps only one of the gull lines has been acquired thus.

I think, however, that Prof. Baer rather overemphasizes (p. 104) the apparent contradiction in the conclusions he reaches from the study of Tetrabothriids and the evidence deduced from a study of the Mallophaga. True, his conclusions are not entirely confirmed by the published work on the feather lice, but this is largely owing to the fact that evidence from the distribution of the Mallophaga is rarely helpful in the elucidation of the relationship between orders of birds. Thus the Mallophaga of the Sphenisciformes and Gaviiformes show no apparent relationship to those of other birds. While, although some of the Mallophaga of the Procellariformes, Pelecaniformes and Charadriiformes do not rule out a possible relationship between these orders, the evidence is in no way conclusive.

Finally, it must always be remembered that the classification of the birds themselves is in some cases still open to doubt, and the characters upon which families are assigned to certain orders may be less dependable than the characters chosen for classifying their parasites. Unfortunately, specialists are not often in a position to evaluate the classification of groups other than their own, and are chary of taking 